Preface

\title{
Supercritical fluid processing of biopolymers and biomedical materials
}

This special issue of the Journal of Supercritical Fluids is devoted to selected papers presented at the workshop on "Supercritical Fluid Processing of Biopolymers and Biomedical Materials" that was held in Madeira, Portugal, during November 16-17, 2010. The workshop was organized by the 3B's (Biomaterials, Biodegradables and Biomimetics) Research Group of the University of Minho, the lead research group of the European Institute of Excellence for Tissue Engineering and Regenerative Medicine.

The workshop was the first workshop specifically focused on this rapidly growing area. The main objective of the workshop was to bring together a group of specialists in this topical area not only to learn about the newest developments and discoveries but also to provide an informal environment for discussions and interactions among all participants, especially the students and the lecturers.

Supercritical fluids offer viable alternatives to conventional processes for the processing of biopolymers and bioactive compounds. The field is continually growing as reflected by the increasing number of papers that are published each year. From the preparation of microparticles to the development of 3D structures, the applications of supercritical fluids have evolved and now present a wide range of alternative methods that take advantage of the tunable properties of supercritical fluids and involve mild operating conditions. However, the advantages of these processes must be weighted against the inconvenience and the costs associated with operating at high pressures.
The current trends in the use of supercritical fluids for tissue engineering include polymer precipitation from gas saturated solutions or by phase separation using carbon dioxide as antisolvent, gas foaming, supercritical fluid assisted phase-inversion, surface modification, extrusion, sterilization or incorporation of bioactive compounds and cells with the aid of supercritical fluids. The workshop covered all these activity areas and are covered in the papers included in this special issue.

Rui L. Reis*

Ana Rita Duarte Joao F. Mano

3B's Research Group - Biomaterials, Biodegradables and Biomimetics, Headquarters of the European Institute of Excellence on Tissue Engineering and Regenerative Medicine, University of Minho, Caldas das Taipas, AvePark, Guimarães, Portugal

* Corresponding author. Tel.: +351 253510900. E-mail address: rgreis@dep.uminho.pt

(R.L. Reis)

27 July 2010 